\title{
IMOBILIZAÇÃO DE BETA-GALACTOSIDASE EM AGAROSE, OBJETIVANDO A OBTENÇÃO DE LEITE COM BAIXO TEOR DE LACTOSE.
}

\author{
Amábile Ferreira Rocha ${ }^{1}$; Andrea Limoeiro Carvalho ${ }^{2}$ \\ 1. Bolsista PEVIC, Graduando em Engenharia de alimentos, Universidade Estadual de Feira de Santana, e-mail: \\ amabilerocha@hotmail.com \\ 2. Orientador, Departamento de Tecnologia, Universidade Estadual de Feira de Santana, e-mail: limoeiro@uefs.br
}

PALAVRAS-CHAVE: Imobilização; ativação; agarose.

\section{INTRODUÇÃO}

O uso de enzimas imobilizadas tem como objetivo possibilitar o reaproveitamento das enzimas em mais de um processo de hidrólise, ou ainda seu uso em processos contínuos, possibilitando uma redução do consumo da enzima necessária para o processo de hidrólise e dos custos de produção destes alimentos específicos através desse reaproveitamento, além de aumentar o ciclo de vida útil desta e facilitar a vida do consumidor ao tornar estes produtos específicos mais acessíveis. Com ela, ocorrem variações no comportamento da enzima podem ser observadas após sua adsorção no suporte, variando inclusive com o tipo de suporte utilizado (MAI; TRAN; LE, 2013).

Diversos estudos com as mais variadas enzimas já foram conduzidos por diferentes autores (COMERLATO, 1995; SILVA et al., 2008; FERNANDES, 2010). A enzima beta-galactosidade, objeto deste estudo, por exemplo, já teve sua carga enzimática e estabilidade térmica e ao $\mathrm{pH}$ avaliada ao ser imobilizada em suportes para obtenção de sensores, embalagens bioativas e reações de hidrólise, sem que um estudo da hidrólise subseqüente fosse conduzido (LATHOUDER et al., 2004; GODDARD; TALBERT; HOTCHISS, 2007; LATHOUDER, et al., 2007; MAHONEY; TALBERT; GODDARD, 2013; MAI; TRAN; LE, 2013; WONG; TALBERT; GODDARD, 2013; ZHAO et al., 2013; ELNASHAR E HASSAN, 2014; WONG, et al., 2014). Outros autores pesquisaram ainda a imobilização de beta-galactosidase em diferentes suportes, avaliando sua atividade após a imobilização, como agarose ativada por brometo de cianogênico (BrCN), agarose-epóxido, glioxil-agarose, MANAE-agarose, glutaraldeídoagarose e MANAE-glutaraldeído (GIACOMINI et al., 2001; VIEIRA, 2009; GONÇALVES, 2013; BRUGNARI et al., 2016; TORALLES et al., 2016).

O presente estudo objetivou a revisão de literatura sobre a caracterização da atividade enzimática da enzima beta-galactosidase como enzima imobilizada em agarose, em diversos trabalhos envolvendo o uso de diferentes tipos de ativação para este suporte, seguido da determinação da atividade da enzima após a imobilização. Numa visão mais ampla, o reaproveitamento da enzima leva a uma redução nos custos do processo, amplificando o mercado consumidor e suprindo parte da carência de produtos derivados do leite para os indivíduos que sofrem de intolerância à lactose, em qualquer idade.

\section{METODOLOGIA}

Para a imobilização enzimática, foi realizada uma revisão de literatura baseada na metodologia do plano de trabalho, nos custos e a viabilidade técnica de execução. 
Foram encontradas metodologias com algumas variações, como diferentes suportes e diferentes substâncias para a ativação da agarose. Dentre as metodologias pesquisadas, foram selecionadas para o desenvolvimento do projeto, a saber: a imobilização em glioxil-agarose 6\% e em MANAE-glutaraldeído (VIEIRA, 2009) e a imobilização em glioxil-agarose (TORALLES et al., 2016).

\section{DISCUSSÃO}

Para avaliação da revisão de literatura realizada, foram necessárias algumas analogias, determinando as metodologias selecionadas para avaliar a imobilização.Por proximidade com a metodologia do plano de trabalho proposto, seus reagentes e equipamentos utilizados, disponibilidade de compra e possibilidade da execução da técnica, uma das metodologias selecionadas para este estudo foi a utilizada na tese "Imobilização da enzima $\beta$-Galactosidase de Kluyveromyces fragilis em agarose e quitosana utilizando diferentes protocolos de ativação”, de autoria de Vieira (2009), na qual foram preparados o gel glioxil-agarose, o gel MANAE e o gel MANAEglutaraldeído, seguida da imobilizaçao em glioxil-agarose $6 \%$ e em MANAEglutaraldeído. O preparo do suporte de glioxil-agarose se deu por esterificação da agarose com glicidol e posterior oxidação com periodato de sódio. O suporte glioxilagarose é então aminado com etilenodiamina $2 \mathrm{M}$, a pH 10, sob agitação suave por $2 \mathrm{~h}$ à temperatura ambiente e o suporte MANAE, por sua vez, é ativado com glutaraldeído, sob agitação à temperatura ambiente por $18 \mathrm{~h}$. Entre os resultados obtidos tem-se que a imobilização da enzima em gel glioxil-agarose não resultou no fornecimento de um derivado ativo, a enzima sofreu inativação em pH 10,05 e a adsorção iônica da enzima em MANAE-agarose teve rendimento de imobilização da ordem de $100 \%$ e forneceu derivados com elevada atividade catalítica.

Além desta, a metodologia utilizada na "Imobilização e cinética da invertase de saccharomyces cerevisiae em agarose”, de Tollares et al.(2016), em que foi preparado o suporte agarose-glioxil, com posterior oxidação com periodato de sódio e imobilização da invertase em agarose-glioxi, também foi selecionada para estudo. Nesta metodologia, a invertase é imobilizada em agarose-glioxil a $25^{\circ} \mathrm{C}$, $50 \mathrm{rpm}$ durante $24 \mathrm{~h}$ em tampão fosfato de sódio $100 \mathrm{mM}$, pH 7,0 e tampão bicarbonato de sódio $100 \mathrm{mM}$, a pH 10. Na suspensão de imobilização foi adicionado boroidreto de sódio (1 mg /mL suspensão), durante 30 minutos com agitação $(100 \mathrm{rpm}), 25{ }^{\circ} \mathrm{C}$, com posterior centrifugação e reconstituição com tampão acetato de sódio 200mmol/L pH 5,0. A ótima imobilização foi obtida em $\mathrm{pH} 10$, durante $24 \mathrm{~h}$ a $50^{\circ} \mathrm{C}, 50 \mathrm{rpm}$ e um suporte ativado de 5 g.

A utilização de diferentes suportes para a ativação da agarose e imobilizações em diferentes extratos e tampões, evidencia as diferentes técnicas de imobilização de enzimas e a gama de possibilidades, parâmetros e aplicações.

\section{CONSIDERAÇÕES FINAIS}

A partir da revisão feita, pode-se concluir que a imobilização de enzimas em diferentes suportes apresenta resultados distintos a depender da enzima utilizada, e sua origem, bem como dos suportes escolhidos para tal. Nesses estudos os autores destacam as numerosas vantagens relacionadas à imobilização enzimática, como o melhor controle das variáveis do processo e reutilização destas para outros processamentos. 


\section{REFERÊNCIAS}

BRUGNARI, T.; PEREIRA, M. G.; FREITAS, E. N.; LIMA, E. P. GARCIA, J. A. A.;. POLIZELI, M. L. T. M.; SOUZA, C. G. M.; PERALTA, R. M. Imobilização da Enzima Lacase de Fungos Ligninolíticos em Suportes de Agarose Ativados Iônica e Covalentemente. In: SEMINÁRIO BRASILEIRO DE TECNOLOGIA ENZIMÁTICA, XII., 2016, Maringá. Anais... . Caxias do Sul: Enzitec, 2016. p. 1 - 4.

COMERLATO, M. H. Imobilização de enzimas no suporte crisotila. 1995. 99p. Tese (Doutorado) Instituto de Química, Unicamp, Campinas, 1995.

FERNANDES, P. Enzymes in food processing: a condensed overview os strategies for better biocatalysts. Enzyme Research, article ID 862537, 2010.

GIACOMINI, C.; IRAZOQUI, G.; BATISTA-VIERA,F.; BRENA, B. Influence of the immobilization chemistry on the properties of immobilized b-galactosidases. Journal of Molecular Catalysis B: Enzymatic. Montevidéu, p. 597-606, 2001.

GONÇALVES, H. B. 'Beta'-D-frutofuranosidases de Fusarium graminearum: produção, purificação, imobilização e determinação das propriedades bioquímicas de enzimas solúveis e secas em Spray dryer. 2013. 97 f. Tese (doutorado) - Programa de pósgraduação em Biotecnologia, Universidade Estadual Paulista Júlio de Mesquita Filho, Instituto de Química de Araraquara, 2013.

MAI, T. H. A.; TRAN, V. N.; LE, V. V. M. Biochemical studies on the immobilized lactase in the combined alginatecarboxymethyl cellulose gel. Biochem. Eng. J., v. 74, p. 81-97, 2013.

SILVA, R. L. F. O. B.; SOUZA, R. R.; SANTANA, J. C. C.; TAMBOURGI, E. B. Imobilização de enzimas de milho maltado em gel. Ciênc. Tecnol. Aliment., v. 28, p. 642-648, 2008.

TORALLES, R.P.; ROSSLER, A.F.; FERREIRA, M. V.; ROMBALDI, C.V.; RUIZ, C. A. Imobilização e cinética da invertase de saccharomyces cerevisiae em agarose. In: Congresso brasileiro de ciência e tecnologia de alimentos, XXV, 2016, Gramado. Anais... . Pelotas: FAURGS, 2016. p. 1 - 6.

VIEIRA, D. C. Imobilização da enzima $\beta$-galactosidade de kluyveromyces fragilis em agarose e quitosana utilizando diferentes protocolos de ativação.2009. 96 f. Dissertação (Mestrado)-Programa de pós-graduação em engenharia química, Universidade Federal de São Carlos, 2009. 